\title{
Immunoglobulin-like domain containing receptor 1 mediates fat-stimulated cholecystokinin secretion
}

\author{
Rashmi Chandra, ${ }^{1}$ Yu Wang, ${ }^{1}$ Rafiq A. Shahid,1 Steven R. Vigna,1,2 \\ Neil J. Freedman, ${ }^{1}$ and Rodger A. Liddle ${ }^{1,3}$ \\ ${ }^{1}$ Department of Medicine and ${ }^{2}$ Department of Cell Biology, Duke University, Durham, North Carolina, USA. \\ ${ }^{3}$ Durham VA Medical Center, Durham, North Carolina, USA.
}

\begin{abstract}
Cholecystokinin (CCK) is a satiety hormone produced by discrete enteroendocrine cells scattered among absorptive cells of the small intestine. CCK is released into blood following a meal; however, the mechanisms inducing hormone secretion are largely unknown. Ingested fat is the major stimulant of CCK secretion. We recently identified a novel member of the lipoprotein remnant receptor family known as immunoglobulinlike domain containing receptor 1 (ILDR1) in intestinal CCK cells and postulated that this receptor conveyed the signal for fat-stimulated CCK secretion. In the intestine, ILDR1 is expressed exclusively in CCK cells. Orogastric administration of fatty acids elevated blood levels of CCK in wild-type mice but not Ildr1-deficient mice, although the CCK secretory response to trypsin inhibitor was retained. The uptake of fluorescently labeled lipoproteins in ILDR1-transfected CHO cells and release of CCK from isolated intestinal cells required a unique combination of fatty acid plus HDL. CCK secretion secondary to ILDR1 activation was associated with increased $\left[\mathrm{Ca}^{2+}\right]_{i}$, consistent with regulated hormone release. These findings demonstrate that ILDR1 regulates CCK release through a mechanism dependent on fatty acids and lipoproteins and that absorbed fatty acids regulate gastrointestinal hormone secretion.
\end{abstract}

\section{Introduction}

Cholecystokinin (CCK) is a classic gastrointestinal hormone that stimulates several gastrointestinal processes, including gallbladder contraction, pancreatic secretion, and satiety. Together, these actions coordinate the ingestion and digestion of food. Diminished CCK secretion or CCK receptor blockade is associated with impaired gallbladder contraction and pancreatic secretion, enhanced hunger, and increased food intake (1-4), whereas exogenous CCK administration stimulates gallbladder contraction and pancreatic secretion, delays gastric emptying, and reduces food intake $(5,6)$.

CCK is produced by discrete enteroendocrine cells (I cells) that reside as single cells scattered among enterocytes in the mucosa of the small intestine. Like most gastrointestinal hormones, CCK is released into the blood following ingestion of a meal, and despite the apical surface being exposed to the lumen of the intestine, the mechanisms by which foods stimulate hormone secretion are largely unknown. It has recently been demonstrated that CCK cells contain calcium-sensing receptors that mediate amino acid-stimulated CCK release $(7,8)$, supporting the concept that cell surface receptors regulate food-stimulated gastrointestinal hormone release. Of the food components that stimulate CCK secretion, fats are the most important. Fat-stimulated CCK release is readily apparent in humans but requires lipolysis of triglycerides to fatty acids of the chain length of dodecanoic acid [C12] or longer (9-11). In vitro, it has been shown that fatty acid aggregates (car-

Conflict of interest: The authors have declared that no conflict of interest exists.

Note regarding evaluation of this manuscript: Manuscripts authored by scientists associated with Duke University, The University of North Carolina at Chapel Hill, Duke-NUS, and the Sanford-Burnham Medical Research Institute are handled not by members of the editorial board but rather by the science editors, who consult with selected external editors and reviewers.

Citation for this article: J Clin Invest. 2013;123(8):3343-3352. doi:10.1172/JCI68587 bon chain length 10 or greater) can stimulate CCK secretion from the enteroendocrine cell line STC-1, and this release is accompanied by an increase in intracellular $\mathrm{Ca}^{2+}\left(\left[\mathrm{Ca}^{2+}\right]_{\mathrm{i}}\right)(12,13)$.

It was recently demonstrated that stimulation of the $G$ protein-coupled receptor 40 (GPR40) present in CCK-EGFP cells by C18 fatty acids, resulted in elevation of $\left[\mathrm{Ca}^{2+}\right]_{\mathrm{i}}$ as well as release of CCK (14). However, CCK cells isolated from $\mathrm{Gpr}^{10^{-/}}$mice also responded to $\mathrm{C} 18$ fatty acids, suggesting that GPR40 is not the sole mechanism by which fatty acids stimulate CCK cells. Another proposed mechanism for CCK release from the intestine is through the action of chylomicrons and other related lipoproteins on CCK cells (15). Fat-stimulated CCK release was inhibited by administration of Pluronic-L81, which blocks intestinal lipoprotein assembly, and intra-arterial infusion of chylous lymph collected from intralipid-fed rats decreased gastric emptying through a CCK-dependent mechanism, raising the possibility that lipoprotein molecules can act on the basolateral rather than the apical surface of CCK cells to stimulate hormone secretion (16).

Immunoglobulin-like domain containing receptor 1 (ILDR1) is a member of the lipoprotein remnant receptor family and shares $31 \%$ sequence identity with the lipolysis-stimulated receptor (LSR) (17). LSR was first identified as a membrane protein that mediated LDL uptake in the presence of fatty acids in homozygous familial hypercholesterolemia fibroblasts deficient in LDL receptor (18). Subsequent studies showed that LSR had a higher affinity for oleate-induced binding of chylomicrons and VLDL rather than LDL and was perhaps involved in the clearance of triglyceride-rich lipoproteins by the liver. Three alternatively spliced isoforms of ILDR1 have been described (17). Two isoforms ( $\alpha$ and $\alpha^{\prime}$ ) contain a putative transmembrane domain and are targeted to the plasma membrane, while the third isoform $(\beta)$ lacks the exons encompassing the transmem- 


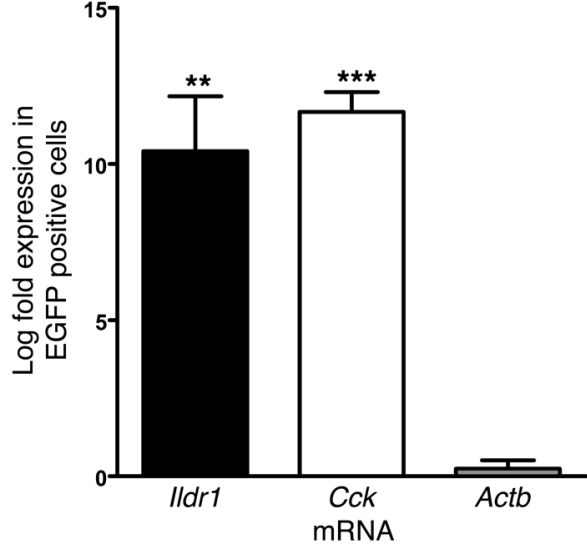

brane domain and is presumably cytoplasmic in location. Given the amino acid similarity between ILDR1 and LSR, we postulated that lipoprotein-fatty acid interactions of ILDR1 may be involved in fatty acid sensing by intestinal CCK cells.

\section{Results}

In an attempt to identify novel receptors and signal transduction pathways regulating CCK secretion, we performed a microarray analysis of CCK cells. CCK cells were enriched to $>90 \%$ purity by FACS of dispersed intestinal mucosal cells from transgenic CCKEGFP mice, which express EGFP under the control of the CCK promoter (ref. 8 and Supplemental Figure 1; supplemental material available online with this article; doi:10.1172/JCI68587DS1). The gene expression profile of CCK-EGFP cells was compared with that of non-EGFP mucosal cells of the small intestine. This array identified overexpression of Ildr1 mRNA in CCK-EGFP cells. Using real-time PCR (RT-PCR), we confirmed that Ildr1 is expressed in CCK cells of the proximal small intestine. RT-PCR demonstrated that Ildr1 mRNA is highly expressed in fluorescent CCK-EGFP

\section{Figure 1}

Relative quantitation of $I l d r 1$, Cck, and Actb gene expression in FACSsorted CCK-EGFP cells using RT-PCR. The fold change (base 2 logarithmic scale) in relative quantity of $I / d r 1, C c k$, and Actb mRNA is shown. Gapdh was used as the normalizer, and RNA isolated from CCK-EGFP-negative cells was used as the calibrator. IIdr1 and Cck mRNA levels were compared with Actb. ${ }^{* *} P<0.01,{ }^{* \star *} P<0.001(n=3$; RNA pooled from 1 to 3 mice for each value).

cells compared with nonfluorescent intestinal mucosal cells (Figure 1). Ildr1 mRNA levels in EGFP-positive cells were not significantly different from Cck mRNA levels, whereas they differed significantly from those of $\beta$-actin. The levels of $\beta$-actin were very similar between EGFP-positive and EGFP-negative cell populations and to those of Gapdh (normalizer). Thus, Ildr1 and Cck were coexpressed in CCK cells of the proximal intestine.

To determine whether ILDR1 behaved similarly to LSR in mediating uptake of lipoproteins in the presence of fatty acids, we used CHO cells transfected with an ILDR1-encoding plasmid (Supplemental Figure 2). ILDR1 expressed in these cells migrated on SDS-PAGE as a band with a $\mathrm{M}_{\mathrm{r}}$ of approximately $100 \mathrm{kDa}$ (Supplemental Figure 2A). Immunostaining of ILDR1-transfected $\mathrm{CHO}$ cells showed that the protein was located on the membrane (Supplemental Figure 2B) as well as in punctate intracellular compartments. The identity of this intracellular compartment(s) has not been determined.

To elucidate the function of ILDR1, we tested whether it could mediate uptake of lipoproteins in the presence of a fatty acid, as has been reported for LSR (19). Uptake of fluorescently labeled lipoproteins (HDL, LDL, VLDL, and chylomicrons) in the presence or absence of C12 was quantitated by automated FACS of fixed cells (ref. 20 and Figure 2). HDL was the only lipoprotein that produced an increase in cellular fluorescence in ILDR1-transfected cells in the presence of C12. The specificity of this effect was demonstrated by competition with unlabeled HDL. These results suggested that, like LSR, ILDR1 may be involved in the binding

\section{Figure 2}

Dil-HDL uptake in $\mathrm{CHO}$ and ILDR1-transfected cells. $\mathrm{CHO}$ and ILDR1-transfected $\mathrm{CHO}$ cells were incubated with Dil-labeled lipoproteins, and cellular fluorescence was measured using FACS. Cells were incubated with $5 \mu \mathrm{g}$ protein $/ \mathrm{ml}$ of Dil-labeled lipoproteins for 2 hours in the absence or presence of a 100 -fold excess of unlabeled lipoproteins and $2 \mathrm{mM}$ C12. Nonspecific fluorescence (observed in the presence of 100 -fold excess of unlabeled lipoproteins) was subtracted from all values. ${ }^{*} P<0.05,{ }^{* * *} P<0.001$ ( $n=3$ experiments). $\mathrm{CM}$, chylomicron.
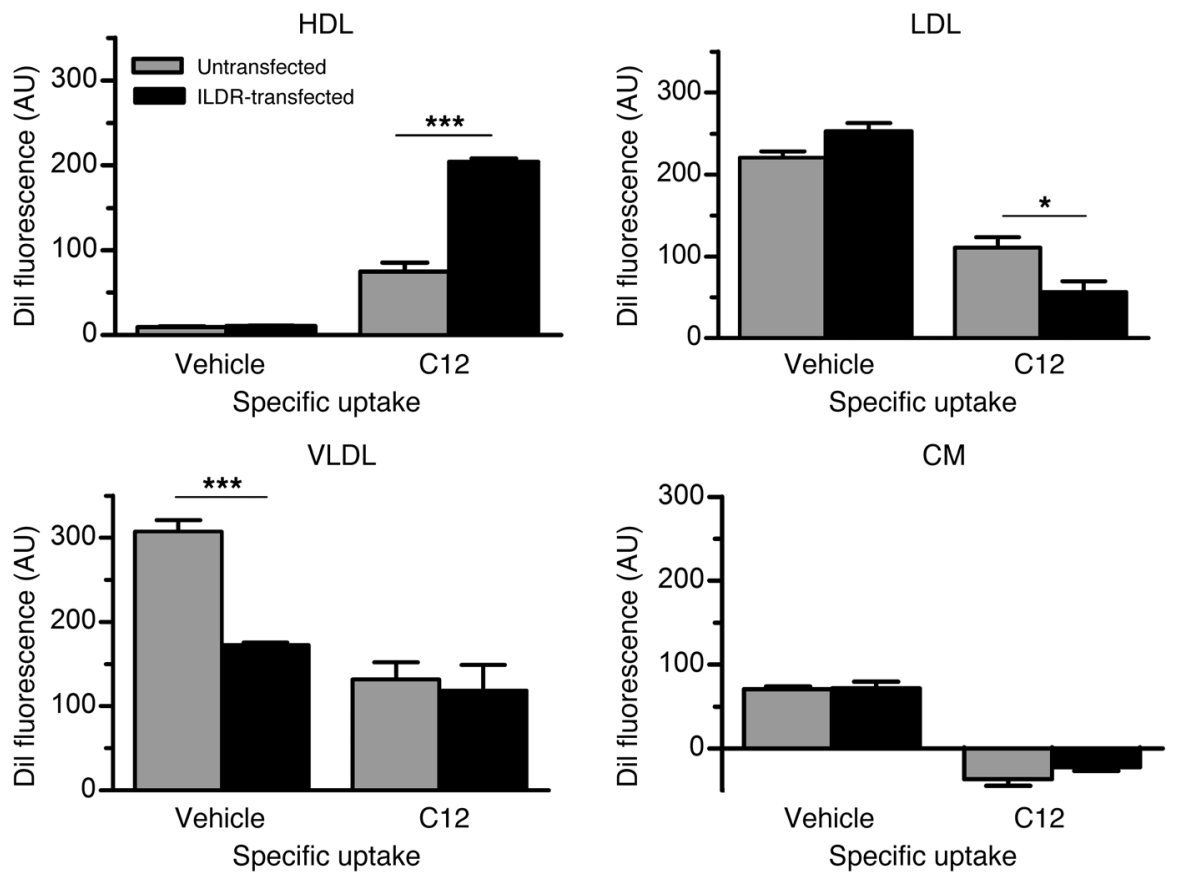

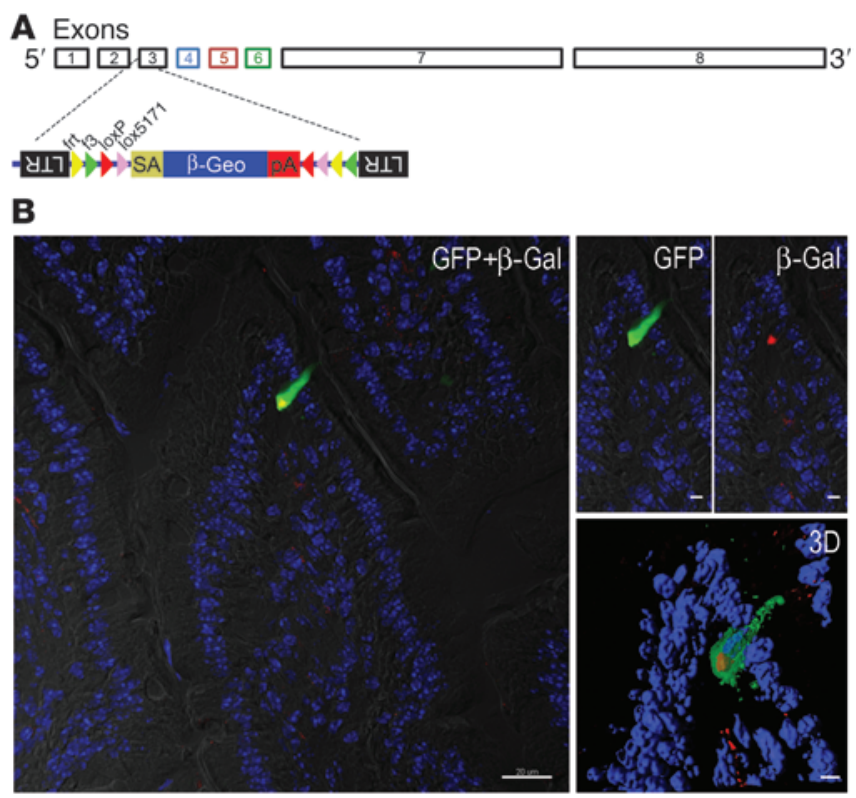

and uptake of lipoproteins (HDL but not chylomicrons, VLDL, or LDL) in the presence of a fatty acid (C12).

In order to determine the role of ILDR1 in regulating CCK secretion, we generated Ildr 1 knockout mice (Ildr1 $1^{-/-}$mice) using ES cells containing a disrupted Ildr1 gene (German Gene Trap Consortium). The targeting vector (Figure $3 \mathrm{~A}$ ) carrying $\beta$-Geo fusion protein with a $5^{\prime}$ splice acceptor was integrated in intron 2 of the Ildr 1 gene. By X-gal staining, $\beta$-galactosidase expression was observed in several tissues as described previously (ref. 17 and R. Chandra and R.A. Liddle, unpublished observations). The expression of $\beta$-galactosidase in intestinal CCK cells was confirmed by coimmunostaining for CCK and $\beta$-galactosidase proteins (Figure 3B). CCK and $\beta$-galactosidase colocalized in $93 \%$ of the CCK-positive cells in the villus, suggesting cellular targeting of Ildr1 gene deletion in CCK cells of the duodenum. Using RT-PCR, we failed to amplify Ildr1 from RNA prepared from GFP-positive intestinal cells of ${\text { Ildr } 1^{-1}}^{-1}$ CCK-EGFP mice (after 40 cycles), whereas it could be amplified from comparable amounts of total RNA (50 ng) isolated from GFP-positive cells of wild-type CCK-EGFP mice. Cck was amplified from intestinal RNA isolated from both wild-type and knockout mice (data not shown).

The effect of Ildr1 deletion on CCK secretion was studied by two independent methods. First, fatty acids were administered to wild-type and Ildr1-/ mice via orogastric gavage $(0.075 \mu \mathrm{mol} / \mathrm{g}$ mouse in $400 \mu \mathrm{l})$, and plasma CCK levels were measured by bioassay (21) 30 minutes later (Figure 4A). With octanoate, dodecanoate, or oleate, wild-type mice demonstrated a typical postprandial increase in plasma CCK levels. However, no increase in plasma CCK levels was observed in Ildr $1^{-/-}$mice. Similar effects were noticed with decanoate and palmitoleate (data not shown). At the time of blood collection, tracer methylene blue dye was detected in the intestinal lumen of both groups of animals, suggesting

\section{Figure 3}

Ildr1 gene deletion and CCK cell-specific expression. (A) The mouse Ildr1 gene was disrupted by insertion of a $\beta$-Geo fusion reporter in intron 2 , resulting in the production of $\beta$-galactosidase in targeted cells. The transmembrane domain is located in exon 4. A cysteine-rich region is present in exon 5 and a dileucine motif is located in exon 6 of human ILDR1. Introns are not drawn to scale. (B) Expression of EGFP and $\beta$-galactosidase in I/dr1-/- CCK-EGFP mouse duodenum was determined by immunostaining frozen sections with antibodies to EGFP (CCK cell reporter) and $\beta$-galactosidase (I/dr1-/- reporter). The left image shows colocalization (yellow) of EGFP (green) and $\beta$-galactosidase (red) antigens; nuclear staining (DAPI) is shown in blue (scale bar: $20 \mu \mathrm{m}$; original magnification, $\times 40)$. The top right images show staining of EGFP (green) or $\beta$-galactosidase (red) (scale bar: $5 \mu \mathrm{m}$ ). The bottom right image is a $3 D$ reconstruction of this cell using Imaris software. The isosurface of the EGFP (green) cytoplasmic staining was rendered transparent to reveal $\beta$-galactosidase staining (red isosurface) and nucleus (blue isosurface) located within the cell (scale bar: $5 \mu \mathrm{m}$ ).

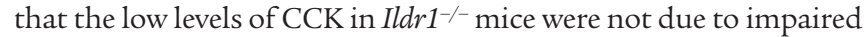
gastric emptying. It is important to note that although dietary fat is the major stimulant of CCK secretion, proteins also cause CCK release through a mechanism that involves intraluminal proteases (22). To determine whether the effects of ILDR1 deficiency were selective for fat-stimulated CCK release, we tested the ability of soybean trypsin inhibitor (SBTI, type II) to stimulate CCK secretion in wild-type and $I l d r 1^{-1-}$ mice (Figure 4B). Orogastric administration of SBTI caused comparable elevations in plasma CCK levels in wildtype and $I l d r 1^{-/-}$mice, indicating that Ildr1-deficient CCK cells are capable of responding to other secretagogues and that fatty acids trigger ILDR1-promoted CCK secretion.
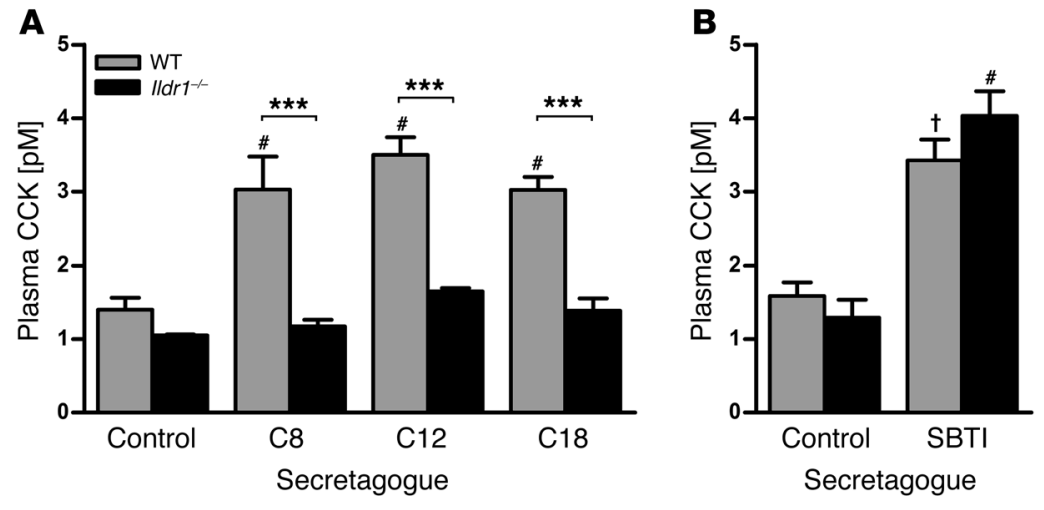

Figure 4

Plasma CCK responses in IIdr1-/- mice. (A) Blood was collected for measurements of plasma CCK concentrations 30 minutes after orogastric administration of octanoate (C8), dodecanoate (C12), or oleate (C18) in wild-type and I/dr1-1- mice. The dose of each fatty acid was $0.0749 \mu \mathrm{mol} / \mathrm{g}$ body weight administered in a volume of 300 to $400 \mu \mathrm{l}$. (B) To determine whether Ildr1 gene deletion was specific for fatty acid-stimulated CCK release, CCK levels were measured in wild-type and $/ / d r 1^{-1-}$ mice that were administered $0.32 \mathrm{mg} / \mathrm{g} \mathrm{mg} \mathrm{SBTI}{ }^{\dagger} P<0.01,{ }^{\sharp} P<0.001$, comparison with basal release within a genotype; ${ }^{\star \star \star} P<0.001$, comparison with basal release between genotypes ( $n=3$ values; plasma from 2 to 4 mice was pooled for obtaining each value). 

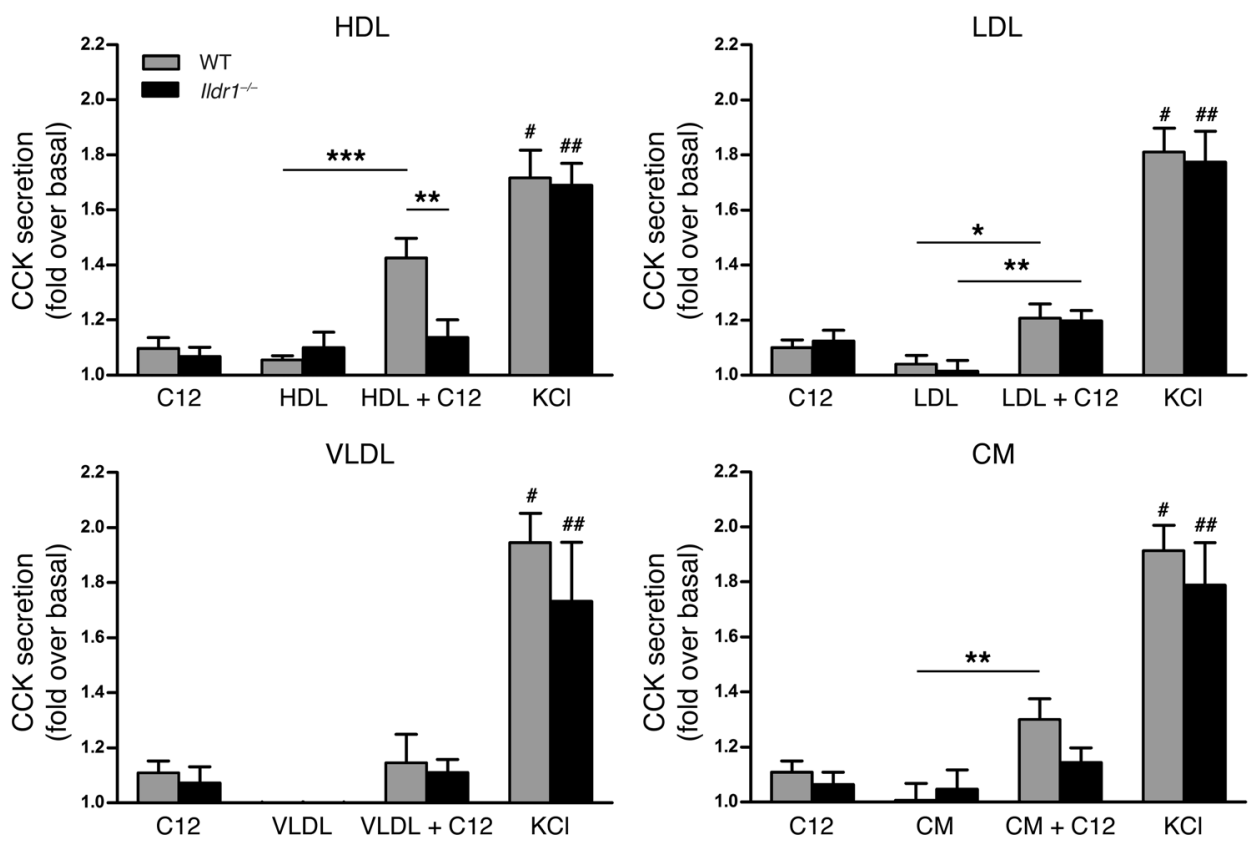

\section{Figure 5}

Effects of fatty acids and lipoproteins on CCK secretion from dispersed intestinal mucosal cells. Mucosal cells were dispersed from intestines of wild-type or $/ / d r 1^{-/-}$mice and incubated with C12 (100 $\mu \mathrm{M})$, lipoproteins $(100 \mu \mathrm{g}$ protein $/ \mathrm{ml})$, or the combination of lipoproteins and $\mathrm{C} 12$. CCK released into the media after 30-minute incubation was measured by RIA. ${ }^{\#} P<0.001$, comparison of secretion in the presence of $\mathrm{C} 12$ with $\mathrm{KCl}$ (within a genotype) (wildtype); \# $P<0.05$, comparison of secretion in the presence of $\mathrm{C} 12$ with

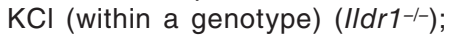
${ }^{\star} P<0.05,{ }^{* \star} P<0.01,{ }^{\star * \star} P<0.001$ ( $n=6-14$ mice).
To determine whether impaired fatty acid absorption could account for reduced CCK secretion in Ildr1-deficient mice, we measured serum triglycerides after a lipid-rich meal in both wild-type and $I l d r 1^{-/-}$mice (Supplemental Figure 3). We found that triglyceride levels increased to similar levels after feeding in both groups of animals, suggesting that lipid absorption may not be markedly altered in knockout mice. In addition, both wild-type and $I l d r 1^{-1}$ mice have similar growth curves on either a normal or high-fat diet, making it unlikely that Ildr1-deficient mice have an alteration in gut permeability to lipids (Supplemental Figure 4).

The effects of fatty acids and lipoproteins on CCK secretion were evaluated in vitro in dispersed intestinal cells from wildtype CCK-EGFP mice and $I l d r 1^{-1-}$ CCK-EGFP mice (Figure 5). Based on fatty acid-promoted HDL uptake in ILDR1-expressing CHO cells, we expected that CCK secretion would be enhanced in the presence of both lipoproteins and fatty acids. Neither fatty acids nor lipoproteins, when administered separately, stimulated CCK release in vitro. However, at concentrations that had no effect individually, HDL in combination with C12 significantly increased CCK release from wild-type CCK cells. In contrast, HDL plus C12 did not stimulate CCK release from Ildr1-deficient CCK cells, indicating that ILDR1 mediated the effects of fatty acids and lipoproteins. In addition, the amount of CCK released from wild-type mouse intestinal cells by $\mathrm{KCl}$ stimulation was not significantly different from that induced by HDL plus C12. CCK release was triggered in wild-type (but

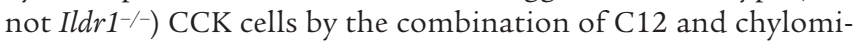
crons and in both wild-type and $I l d r 1^{-/-}$mice by the combination of C12 and LDL. However, there was no statistical difference between the wild-type and $I l d r 1^{-/-}$genotypes, as was observed for HDL plus C12.

Changes in intracellular calcium concentrations are critically important for regulated CCK secretion $(23,24)$. To determine whether $\left[\mathrm{Ca}^{2+}\right]_{\mathrm{i}}$ is elevated in ILDR1-stimulated CCK secretion and to confirm whether fatty acids and lipoproteins act directly on CCK cells, we examined the effects of lipoproteins and fatty acids on calcium fluorescence in FACS-purified CCK-EGFP cells from both wild-type and Ildr1 ${ }^{-/-}$CCK-EGFP mice loaded with the calcium-sensitive dye, X-rhod-1 (Figure 6, A and B). Minimal calcium transients were induced in wild-type and $I l d r 1^{-/-}$CCK-EGFP cells by preparations of C12 $(100 \mu \mathrm{M})$, HDL, LDL, VLDL, or chylomicrons (all lipoproteins were at $100 \mu \mathrm{g}$ protein $/ \mathrm{ml}$ ). However, the combination of HDL and C12 caused a substantial increase in $\left[\mathrm{Ca}^{2+}\right]_{\mathrm{i}}$ in wild-type CCK-EGFP cells but not $\mathrm{Ildr1^{-/- } \mathrm { CCK } -}$ EGFP cells. Under all conditions, cell viability was confirmed by an appropriate $\left[\mathrm{Ca}^{2+}\right]_{\mathrm{i}}$ response to depolarizing concentrations of $\mathrm{KCl}$. The percentages of EGFP-positive cells (wild-type and $\left.I l d r 1^{-/-}\right)$that responded to lipoproteins, lipoproteins and C12, and $\mathrm{KCl}$ are shown in Figure 6C (HDL) and Supplemental Figure 5 (LDL, VLDL, and chylomicrons). Intestinal cells from $\mathrm{Iddr} \mathrm{1}^{-/-} \mathrm{CCK}-$ EGFP mice showed elevation of $\left[\mathrm{Ca}^{2+}\right]_{i}$ when treated with L-phenylalanine (Figure 4 and Supplemental Figure 6), suggesting that these cells were capable of responding to amino acid stimulation. This result is in accordance with the increase of plasma CCK levels observed in $\mathrm{Ildr} \mathrm{1}^{-/-}$mice after orogastric gavage of SBTI.

\section{Discussion}

CCK is released from intestinal cells by the actions of amino acids and fatty acids. In this study, we show that a receptor, ILDR1, with novel function is selectively expressed in the CCK-producing enteroendocrine cells of the small intestine and modulates fatty acid and lipoprotein-mediated CCK secretion. In the absence of ILDR1, fatty acids were unable to stimulate the release of CCK, suggesting that ILDR1 is essential for this process. Since GPR40 has previously been shown to mediate fatty acid-stimulated CCK release (14), it is possible that both GPR40 and ILDR1 play physiologic roles in CCK release. However, ILDR1 appears to be critical for fatty acid-mediated CCK release, as knockout mice exhibited only basal levels of CCK in response to oral administration of fatty acids. Ildr1 $1^{-1-}$ mice retain the ability to release CCK in response to SBTI, suggesting that mechanisms for protein-induced signal transduction and exocytosis were unaffected in CCK cells lacking 
A

Basal

HDL

$\mathrm{HDL}+\mathrm{C} 12$

$\mathrm{KCl}$

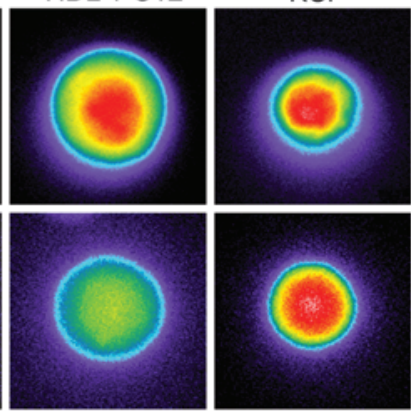

Basal

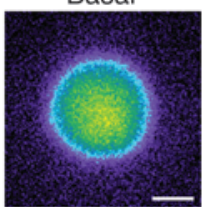

LDL
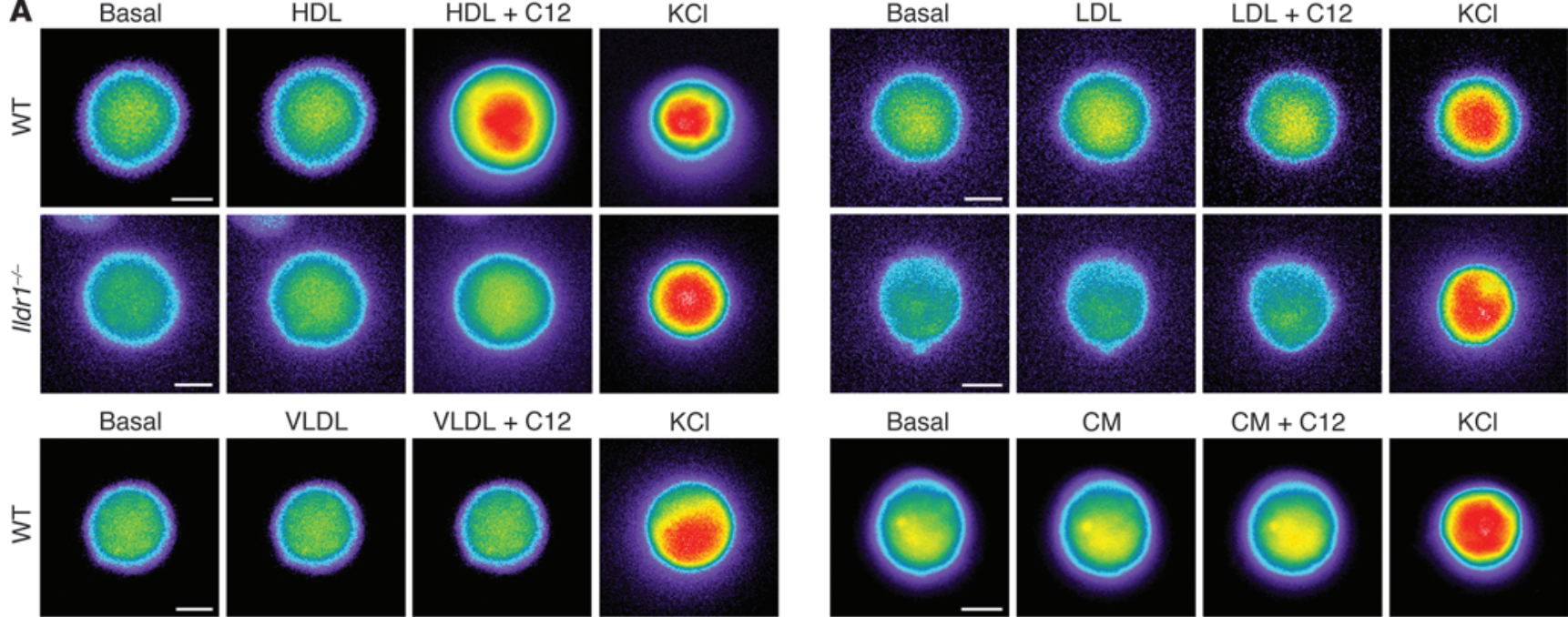

$\mathrm{KCl}$

Basal
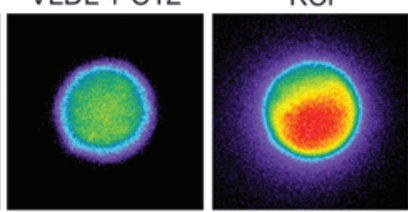

$\mathrm{CM}$
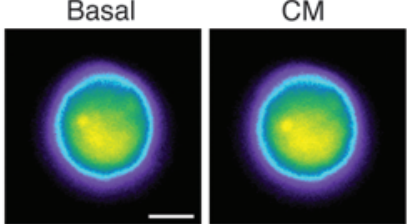

$\mathrm{CM}+\mathrm{C} 12$

$\mathrm{KCl}$
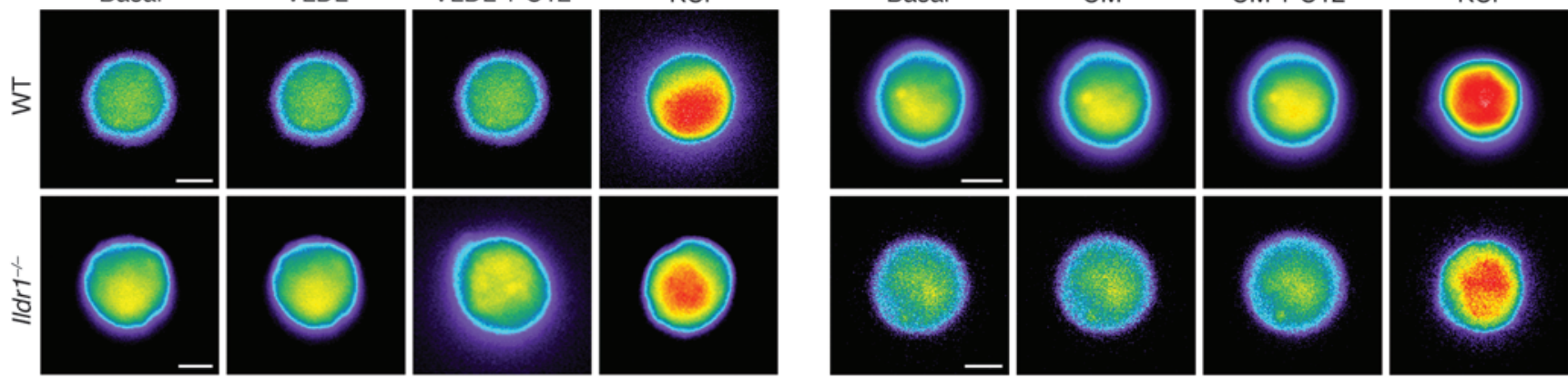

B

WT
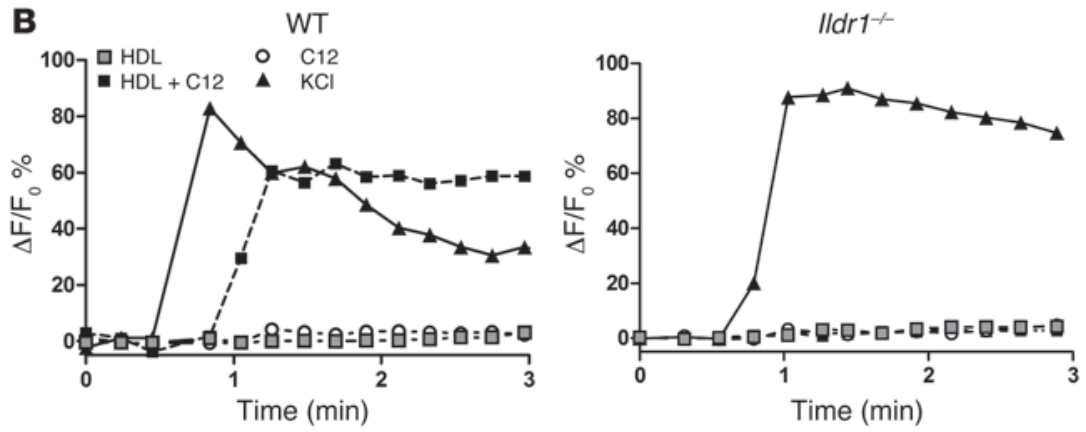

C

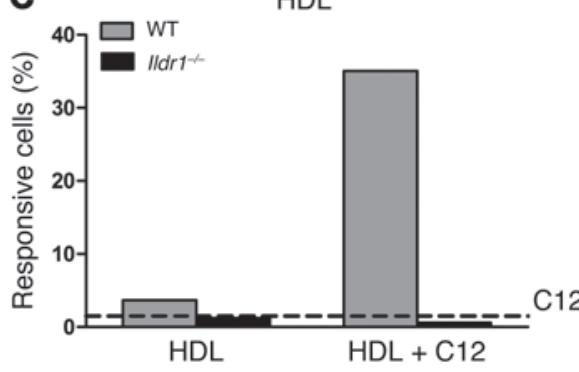

Figure 6

Effects of fatty acids and lipoproteins on intracellular calcium fluorescence in CCK cells. CCK-EGFP cells were isolated from the intestines of wild-type CCK-EGFP and I/dr1-l- CCK-EGFP mice and enriched by FACS. Cells were loaded with calcium-sensitive dye (X-rhod-1) and incubated first with lipoproteins $(100 \mu \mathrm{g}$ protein/ml) or $\mathrm{C} 12(100 \mu \mathrm{M})$, followed by lipoprotein plus $\mathrm{C} 12$, and finally with $\mathrm{KCl}(50 \mathrm{mM})$. (A) The responses of representative wild-type CCK-EGFP or Ildr1 ${ }^{-1-}$ CCK-EGFP cells to lipoproteins and lipoprotein plus $\mathrm{C} 12$ are shown. Change in fluorescence from green to yellow to red indicates elevation in $\left[\mathrm{Ca}^{2+}\right]_{i}$. An increase in $\left[\mathrm{Ca}^{2+}\right]_{\mathrm{i}}$ with $\mathrm{KCl}$ was used to confirm the viability of cells at the conclusion of each experiment. Results are representative of at least 3 experiments. (B) Change in fluorescence intensity in wild-type CCK-EGFP and IIdr1-/CCK-EGFP cells to $\mathrm{C} 12$ alone, HDL alone, HDL plus C12, and $\mathrm{KCl}$. (C) Percentage of wild-type CCK-EGFP and I/dr1 ${ }^{-/-}$CCK-EGFP cells that showed at least a $10 \%$ increase in $\mathrm{Ca}^{2+}$ fluorescence in response to HDL or HDL plus $\mathrm{C} 12$. The percentage of cells responding to $\mathrm{C} 12$ alone is represented by the dashed line. Scale bar: $5 \mu \mathrm{m}$.

ILDR1. Impaired CCK secretion in $I l d r 1^{-1-}$ mice appears to be a direct effect on CCK cells and not through other mechanisms, such as delayed gastric emptying. Addition of methylene blue to the fatty acid solutions showed that the administered fatty acid solutions reached the ileum of wild-type and knockout mice within 30 minutes, suggesting that gastric emptying was qualitatively similar in both control and knockout mice.

Measuring CCK release from in vitro cell preparations has been challenging. Primary CCK cells do not grow well in culture, and CCK-producing cell lines such as STC-1 differ from CCK cells in many important ways. For example, STC-1 cells contain many other hormones besides CCK, and they do not express the same repertoire of receptors as primary CCK cells (R. Chandra and R.A.
Liddle, unpublished observations). In particular, we discovered that STC-1 cells do not express ILDR1. In attempting to study CCK release in vitro, we were unable to reproducibly measure regulated CCK secretion from CCK-EGFP cells after FACS, presumably because sufficient numbers of healthy, responsive cells could not be obtained. As an alternative, we examined dispersed intestinal mucosal cells that contained approximately $0.5 \%$ CCK cells. In these studies, $\mathrm{C} 12$ and individual lipoproteins alone had little effect on CCK release, and it was only with the combination of lipoproteins and C12 (primarily HDL) that a significant increase in CCK release was observed. We also observed minor effects of the combination of C12 and LDL as well as chylomicrons and C12 on CCK release. Since these effects were not observed in DiI uptake 


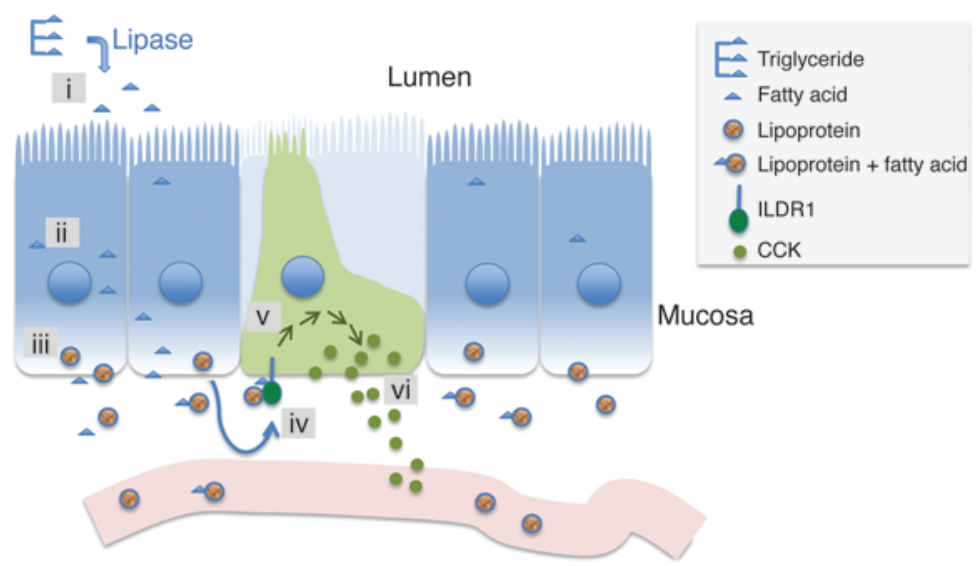

Figure 7

Model of ILDR1 regulation by fatty acids and lipoproteins. Ingested lipids in the form of triglycerides are hydrolyzed by lipases within the intestinal lumen to emulsified 2-monoacyl glycerol and fatty acids (i), which are absorbed by enterocytes (ii) (shown in blue). Long chain fatty acids are reformed into triglycerides and secreted from the basolateral surface of enterocytes. Smaller long chain fatty acids such as $\mathrm{C} 12$ transit the enterocyte without modification and have ready access to the basolateral surface of CCK cells (shown in green). In addition to chylomicrons, $\mathrm{HDL}$ is also produced by enterocytes (iii); thus, CCK cells are exposed to both fatty acids and intestinal lipoproteins following a fat meal. The combination of fatty acids (e.g., C12) and HDL activates ILDR1 (iv), elevating $\left[\mathrm{Ca}^{2+}\right]_{\mathrm{i}}(\mathrm{v})$, which ultimately causes CCK secretion (vi). CCK is released from the basolateral surface into the paracellular space in which it is taken up into the blood to exert effects on distant organs (e.g., pancreas, gallbladder, and nerves).

experiments or during measurements of $\mathrm{Ca}^{2+}$ fluorescence in wildtype and $\mathrm{Ildr1}^{-/-}$CCK-EGFP cells, the relationship with ILDR1 function remains to be determined.

Calcium signaling in CCK cells has been shown to be critically important for regulated hormone secretion $(8,25,26)$. Several physiological secretagogues (such as monitor peptide and amino acids) as well as exposure to depolarizing concentrations of $\mathrm{KCl}$ increase $\left[\mathrm{Ca}^{2+}\right]_{i}$, which is linked to hormone release $(7,8,23,24)$. In this study, involvement of calcium signaling in ILDR1-stimulated CCK secretion was demonstrated by comparing $\left[\mathrm{Ca}^{2+}\right]_{\mathrm{i}}$ in wild-type and Ildr1 $1^{-/}$CCK-EGFP cells. The combination of HDL and $\mathrm{C} 12$ induced an increase in $\left[\mathrm{Ca}^{2+}\right]_{i}$ in wild-type mice but not knockout mice. Our findings differ somewhat from observations in which fatty acids (C18) alone stimulated CCK release from FACS-enriched CCK cells, an effect that was partially reduced in CCK cells from Gpr40-deficient mice (14). Perhaps these differences are due to the viability of cells following FACS. Nevertheless, it appears that ILDR1 plays a major role in the regulation of fatty acid-stimulated CCK secretion, since CCK release is completely eliminated in $\mathrm{Ildr1^{-/ }}$ mice.

Infusion of ${ }^{3} \mathrm{H}$-triolein in rats demonstrated that the maximum uptake of fats occurs in the duodenum and proximal jejunum of the small intestine (27) where a majority of the CCK cells are located. It has previously been shown that the major lipoproteins secreted by the intestine are chylomicrons and VLDL (28). Glickman and colleagues have demonstrated that the intestine secretes discoidal and spherical HDL particles of distinct composition $(29,30)$, and it is now known that about $30 \%$ of plasma HDL is synthesized by intestinal mucosal cells (31). The pathways for the synthesis and secretion of these 3 lipoproteins appear to be segregated $(32,33)$. Chylomicrons are produced during the "fed" condition, whereas VLDL is synthesized during fasting. In addition, these 2 lipoproteins are present in separate vesicles in enterocytes and have different rates of synthesis. While chylomicrons and VLDL are believed to be assembled in the endoplasmic reticulum and Golgi and exocytosed from enterocytes (34), recent evidence discovered during a study of Tangier disease suggests that nascent HDL particles are assembled extracellularly $(33,35)$. That HDL is synthesized under conditions of feeding suggests that HDL is available to stimulate the ILDR1 receptor located on CCK cells.

ILDR1 shares 31\% amino acid identity with LSR (17), and this homology is distributed over the entire sequence of the receptor. ILDR1 behaves similarly to LSR, in that uptake of HDL in the presence of C12 occurred in stably transfected CHO cells. The mechanism by which ILDR 1 interacts with HDL and C12 is yet to be elucidated. It is possible that the HDL particle is taken up inside the cell by endocytosis, as has been shown for LDL receptors and LDL receptor-related proteins (LRPs) $(36,37)$. Our finding that DiI-labeled HDL uptake is enhanced in ILDR1-transfected cells indicates that either ILDR1 undergoes internalization or HDL binding is of sufficient duration to allow exchange of DiI from the outside to the inside of the cell. LSR is highly enriched in the endosomal compartment of rat hepatocytes; endosomal membranes showed greater than 10 -fold oleate-induced ${ }^{125}$ I-LDL binding compared with the plasma membranes (38). A receptor internalization motif (Y-X-X- $\phi$ where $\phi$ is a hydrophobic amino acid such as F, I, L, M, V) is present in ILDR1 at amino acid 459. This motif has been shown to be important for clustering of receptors in clathrin-coated pits by the $\mu$ chain of AP2 (39).

Lipoprotein receptors, including the LDL receptor and lipoprotein remnant receptors, recognize specific apolipoproteins present on the surface of the lipoprotein particles. Although we do not know which apolipoproteins specifically interact with ILDR1, the main candidates are lipoproteins that are present in HDL. Our preliminary data, obtained by immunoblotting of HDL, show that it contains apo A-I and apo A-II but not detectable amounts of apo A-IV or apo E. If lipid feeding increases the production of HDL, then it is logical to postulate that the apolipoproteins associated with HDL in the intestine should also undergo increased synthesis. Magun et al. have shown that lipid feeding increases the amount of apo B and apo A-I in the intestine (40), while Tso and coworkers have demonstrated an increase in the levels of apo A-IV after feeding of intralipid $(27,41)$. Apo A-IV has been shown to play a role in the short-term control of food intake (42-44). Chylous lymph collected from triglyceride-fed rats as well as injections of apo A-IV reduced gastric motility (45), and this effect was lost after denervation of vagal afferents or by application of devazepide (CCK1 receptor antagonist) (15), suggesting that the effects were mediated by CCK. Apo A-IV-mediated effects could account for the increased CCK secretion observed in the presence of both chylomicrons and C12 in intestinal cells from wild-type mice. LSR has been shown to bind apo B and apo E, while apo C-III inhibits the binding of LSR to chylomicrons and VLDL but not LDL (19). The apolipoproteins involved in the interaction of ILDR1 with HDL will be the subject of future investigations. 
ILDR1 is expressed in a variety of tissues (17) (R. Chandra and R.A. Liddle, unpublished data). Recently, Ildr1 mRNA has been localized to hair and supporting cells present in the organ of Corti, and it was found that mutations in Ildr1 lead to DFNB42, a type of nonsyndromic autosomal recessive hearing impairment (46). It was recently demonstrated that LSR is essential for the formation of tricellular tight junctions and targeting of tricellulin to these junctions (47). Tricellulin is expressed in the inner ear, and mutations in this gene have been linked to DFNB49 (48), suggesting that the pathogenesis of this impairment may involve aberrations in LSR-promoted tricellular tight junction formation, which require proper targeting of tricellulin. Similar to LSR, it now appears that ILDR is also involved in targeting of tricellulin to the tight junctions in the inner ear and elsewhere in the body (49). There is a growing body of evidence to suggest that the lipoprotein receptors possess multiligand, multifunctional capabilities (50). LRPs were originally identified for their role in the uptake of chylomicron remnants and lipoprotein metabolism in the liver. However, LRPs have now been shown to interact with 30 different ligands and perform diverse roles such as uptake of lipoproteins, glucose regulation, transport of ligands across the blood-brain barrier, and Wnt/ $\beta$-catenin signaling (51-54). Similarly, the cell surface HDL receptor SR-BI is involved in cholesterol uptake, vitamin $\mathrm{E}$ transport, host defense, and removal of apoptotic cells $(55,56)$. It is therefore plausible that ILDR1 performs distinct functions in different tissues.

Our studies demonstrate that $I l d r 1^{-/-}$mice do not lack CCK, and can secrete CCK in response to SBTI, but have impaired responses to fat-stimulated CCK release. The reason that CCK cells or other hormone-secreting cells of the gastrointestinal tract are distributed as single cells among absorptive cells of the gut is unknown. Our findings provide a possible explanation (Figure 7). Ingested fat (in the form of triglycerides) in the intestinal lumen is catabolized by lipases to 2-monoacylglycerol and fatty acids that are absorbed by enterocytes. Larger chain fatty acids are reesterified, packaged, and released from the basal surface of enterocytes, while medium-large chain fatty acids (C8-C12) are released directly from enterocytes (57). The intestine is also a major source of HDL $(29,30,35)$. Therefore, CCK cells, which are surrounded by enterocytes, would be exposed to both HDL and fatty acids released from the basal surface of enterocytes. Although the apical surface of many CCK cells is exposed to the intestinal lumen, our findings suggest that fatty acids, by virtue of their requirement for HDL to activate ILDR1, act on the basal surface of CCK cells to stimulate hormone secretion. This hypothesis is in agreement with the observation that disruption of lipoprotein assembly with Pluronic-L81 inhibited CCK secretion (15) and that we were unable to detect HDL in the lumen of the intestine (Supplemental Figure 7). Immunostaining of ILDR1 in CCK cells was not sufficiently robust to localize ILDR1 to the apical versus basolateral surface, so visual proof of this hypothesis remains outstanding. Nevertheless, this study indicates that CCK secretion is a regulated process resulting from the combined actions of locally released lipoproteins and intestinally absorbed fatty acids to activate ILDR1.

\section{Methods}

Transgenic and knockout mice. CCK-EGFP transgenic mice were procured from MMRRC (University of Missouri). The colony was propagated by mating CCK-EGFP transgenic mice to wild-type Swiss Webster mice (Charles River Laboratories International Inc.) at each generation (58).
Ildr $1^{-/-}$mice were generated at the Duke Neurotransgenics Facility using the gene-trapped ES cell clone D178D03 TBV-2 cell line (Helmholtz Zentrum Munchen). The targeting vector rFlipROSA $\beta$ geo (Cre) contained a 5 ' splice acceptor site, followed by $\beta$-galactosidase and neomycin phosphotransferase fusion gene insert ( $\beta$-geo), and finally a bovine growth hormone polyadenylation sequence. The vector was randomly integrated in intron 2 (197 bp internal to the exon 2/intron 2 boundary) of the Ildr 1 gene. ES cells were grown on irradiated mouse embryonic fibroblasts for 2 passages, and the presence of the insert was verified by PCR. These ES cells were injected into C57BL/6 blastocysts and transferred to a pseudopregnant female. One fertile chimeric ( $95 \%$ chimeric by coat color) male mouse was born and mated to C57BL/6J mice. Later, the mice were transferred to the Swiss Webster background by back crossing 6 times. Knockout mice were genotyped by PCR using the following primers: Ildr1 forward (located in exon 2) 5'CTGTCCTTGCTAGTCACAGTCC, Ildr 1 reverse 5'GCTGACTTGAGGTCCCACAT (located in intron 2, beyond the insertion of the $\beta$-Geo vector), and lac $Z$ reverse 5 'CAAGGCGATTAAGTTGGGTAACG. The $2 \mathrm{Ildr} 1$ primers amplified a 464-bp band from genomic DNA isolated from wildtype and heterozygous mice, while the Ildr 1 forward and lac $Z$ reverse primers yielded a 1,215-bp band from DNA of heterozygous and knockout mice. The $\mathrm{Ildr}^{-/-}$mice (on Swiss Webster background) were mated to CCK-EGFP transgenic mice to create $I l d r 1^{-/-}$CCK-EGFP mice.

RNA isolation. Intestinal cells were dissociated and subjected to FACS as described previously (8). RNA was isolated using the RNeasy Micro Kit (Qiagen) following manufacturer's recommendations. RNA was analyzed on a Picochip (Agilent 2100 Bioanalyzer) for determination of concentration and integrity. RNA from up to 3 mice was pooled to generate one sample for RT-PCR.

Microarray data. RNA isolated from equal numbers of EGFP-positive and EGFP-negative intestinal mucosal cells was analyzed for gene expression by microarray (Affymetrix GeneChip Mouse Genome 4302.0 Array). Data have been deposited in the NCBI GEO database (accession no. GSE47196).

RT-PCR. 50 ng total RNA was reverse transcribed using the Quantiscript Reverse Transcription Kit (Qiagen). The cDNA was preamplified using TaqMan Preamp Master Mix $\left(95^{\circ} \mathrm{C}\right.$ for 10 minutes, 1 cycle; $95^{\circ} \mathrm{C}$ for $15 \mathrm{sec}-$ onds, $60^{\circ} \mathrm{C}$ for 4 minutes, 14 cycles). Quantitative RT-PCR was performed with TaqMan gene expression assays (Applied Biosystems) on Stratagene's Mx3000P QPCR System. Amplification was performed using the following cycle: $50^{\circ} \mathrm{C}$ for 2 minutes $\left(1\right.$ cycle); $95^{\circ} \mathrm{C}$ for 10 minutes $\left(1\right.$ cycle); $95^{\circ} \mathrm{C}$ for 15 seconds ( 40 cycles); and $60^{\circ} \mathrm{C}$ for 1 minute ( 40 cycles). The assay IDs of the inventoried mouse TaqMan gene expression assays used in this experiment are as follows: Ildr1 (Mm00506487_m1), Cck (Mm00446170_ m1), Actb (Mm02619580_g1), and Gapdh (Mm99999915_g1). The mRNA expression values were compared using the $\Delta \Delta \mathrm{C}_{\mathrm{t}}$ calculations. The expression of target genes in EGFP-positive CCK-producing cells was compared with that in the non-EGFP-positive cells (calibrator). Data were normalized to Gapdh mRNA expression.

Transfection of ILDR1 in CHO cells. An Ildr1 cDNA clone in PCMV-SPORT6 (accession BC057644, ID 4912789) was purchased from Open Biosystems. It was sequenced in its entirety and the coding sequence was amplified by PCR. During amplification, an HA-tag sequence (YPYDVPDYA) was introduced at the intracellular $\mathrm{C}$ terminus of the $\mathrm{cDNA}$. The PCR product was restricted and cloned in the NotI and XhoI sites of pcDNA 3.1/Zeo(-). Recombinant clones were sequenced prior to transfection into $\mathrm{CHO}$ cells using Lipofectamine 2000 (Life Technologies). Stably transfected cells were selected with Zeocin (Life Technologies), and individual drug-resistant colonies were picked and expanded for screening. Cells from several lines were grown in Lab-Tek Chamber Slides (Nalge Nunc International) and evaluated for expression of ILDR1 by HA-tag immunofluorescence. One of the lines containing highly expressed ILDR1 was chosen for DiI uptake experiments. 
Immunochemistry. Immunochemistry was performed as described previously (58). Ildr1 $1^{-/}$CCK-EGFP mice and wild-type littermates were perfused with $3.5 \%$ paraformaldehyde, and the proximal small intestine was harvested, post-fixed, cryopreserved, and flash frozen in OCT. Five- to 20-micron frozen sections were collected on glass slides, fixed for 10 minutes at $-5^{\circ} \mathrm{C}$ in a $50 \%$ mixture of methanol and acetone, and air dried for $30 \mathrm{~min}-$ utes. After rinsing in PBS, sections were blocked with $10 \%$ donkey serum in TBST (10 mM Tris-HCl, pH 8.0, $150 \mathrm{mM} \mathrm{NaCl}, 0.1 \%$ Triton X-100) and incubated in a mixture of goat EGFP (1:1,000 dilution, Abcam) and chicken $\beta$-galactosidase polyclonal antibodies (1:100 dilution, Abcam) overnight at $4^{\circ} \mathrm{C}$ in a humidified chamber. Following washes with TBST, secondary antibodies (donkey anti-goat conjugated to DyLight 488 and donkey antichicken conjugated to DyLight 549; Jackson ImmunoResearch Laboratories Inc.) were added for 1 hour at room temperature. Slides were rinsed, counterstained with DAPI (Biochemika), and mounted in ProLong Gold anti-fade reagent (Invitrogen Corporation).

Images were acquired using a Zeiss 510 inverted confocal microscope. Single optical sections or Z-stacks were collected with excitation at $405 \mathrm{~nm}$ (DAPI), $488 \mathrm{~nm}$ (DyLight 488), and $561 \mathrm{~nm}$ (DyLight 549) and emission filters of BP420-480, BP505-550, and LP575.3D images were rendered from Z-stacks using Imaris software (Bitplane Inc.).

Lipoprotein isolation. Lipoproteins were isolated from human plasma as described previously (59-61). Blood $(60 \mathrm{ml})$ from fed or fasted individuals was collected in the presence of EDTA $(3.2 \mathrm{mM})$, chloramphenicol $(80 \mu \mathrm{g} / \mathrm{ml})$, sodium azide $(0.1 \mathrm{mg} / \mathrm{ml})$, gentamicin $(80 \mu \mathrm{g} / \mathrm{ml})$, and protease inhibitors (Complete Protease Inhibitor Cocktail tablets, Roche Applied Science) and centrifuged at $1,500 \mathrm{~g}$ (average $\mathrm{g}$ ) for 10 minutes at $4^{\circ} \mathrm{C}$. The plasma was carefully aspirated, and lipoproteins were harvested by floatation on $\mathrm{KBr}$ solutions of the following densities: VLDL, $1.006 \mathrm{~g} / \mathrm{ml}$ fraction; LDL, $1.019-1.063 \mathrm{~g} / \mathrm{ml}$ fraction; and HDL, $1.1365-1.21 \mathrm{~g} / \mathrm{ml}$ fraction. Centrifugations were performed using a Ti70 rotor at 120,000 $g$ (average $g$ ) for 28 hours at $16^{\circ} \mathrm{C}$. Chylomicrons were collected after layering the plasma with a solution of $0.9 \% \mathrm{NaCl}$ and $0.5 \mathrm{mM}$ EDTA, $\mathrm{pH} 7.4$ (density $1.066 \mathrm{~g} / \mathrm{ml}$ ), and centrifuging for 20 minutes at $111,100 \mathrm{~g}$ (average $\mathrm{g}$ ) in an SW41 rotor. All lipoproteins were refloated on the appropriate density $\mathrm{KBr}$ solution, dialyzed 3 times against saline at $4{ }^{\circ} \mathrm{C}$, flushed with nitrogen gas, and used within 1 to 2 weeks. Protein estimation was performed by a modified Lowry assay (Pierce, Thermo Fisher Scientific). Lipoproteins preparations were evaluated by electrophoresis on TITAN GEL Lipoprotein agarose gels (Helena Laboratories) until the product was discontinued. They were also analyzed by visualization on SDS-PAGE gels and by Western blotting using Apo A-I, Apo A-II, Apo A-IV, and Apo E antibodies (data not shown). The protein profile of various preparations was very comparable. The stock lipoprotein solutions were diluted directly in the assay media or buffer as described below.

Uptake of DiI-labeled lipoproteins in CHO and ILDR1-transfected cells. Lipoproteins were labeled with DiI by the method of Pitas and colleagues $(62,63)$. DiI-labeled lipoprotein uptake assays were performed by growing ILDR1-transfected and untransfected CHO cells for 48 hours in Ham's F12 media containing $5 \%$ calf lipoprotein-deficient serum (LPDS, prepared by floating lipoproteins at $1.25 \mathrm{~g} / \mathrm{ml} \mathrm{KBr}, 104 \mathrm{mg} / \mathrm{ml}$ ) with or without Zeocin (Life Technologies). On the day of the experiment, fresh media (Ham's F12 media plus $5 \%$ calf LPDS, $50 \mathrm{mg} / \mathrm{ml}$ ), containing $5 \mu \mathrm{g}$ protein $/ \mathrm{ml}$ DiI-labeled lipoproteins in the presence or absence of $\mathrm{C} 12$ dissolved in isopropanol (930 $\mathrm{mM}$ stock, $2 \mathrm{mM}$ final concentration) or unlabeled lipoproteins (100-fold excess), was added to the cells. C12 was added as described by Bihain and Yen (18). After incubation for 2 hours at $37^{\circ} \mathrm{C}$, cells were chilled on ice for 10 minutes and washed 2 times with $2 \mathrm{ml}$ ice-cold PBS containing $0.1 \%$ BSA. After a final wash with cold PBS, $0.2 \mathrm{ml} 0.025 \%$ trypsin-EDTA was added for 2 minutes. Trypsin-EDTA was carefully removed by aspiration, and cells were resuspended in $0.5 \mathrm{ml}$ PBS and added to tubes containing cold $3 \%$ paraformaldehyde, $\mathrm{pH}$ 7.4. After 30 minutes of fixation at $4{ }^{\circ} \mathrm{C}$, cells were analyzed for DiI uptake on a FACStar Plus machine (Becton Dickinson) equipped with an argon laser tuned to $515 \mathrm{~nm}$ as described previously (20).

Measurement of CCK by orogastric infusion of fatty acids. Fatty acids were dissolved in $0.1 \mathrm{M}$ sodium carbonate by sonicating for 4 minutes until no particles were visible. Immediately prior to orogastric administration, concentrated $\mathrm{HCl}$ was added and the $\mathrm{pH}$ of the solution was adjusted to approximately 8.5 . The $\mathrm{pH}$ of the vehicle ( $0.1 \mathrm{M}$ sodium carbonate) was also adjusted to 8.5 . A dose of $0.0749 \mu$ moles fatty acid/g mouse was given in approximately $400 \mu \mathrm{l}$ volume. SBTI (type II, Sigma T-9128, Sigma-Aldrich) was dissolved in $0.9 \% \mathrm{NaCl}$ solution and administered at a dose of $0.32 \mathrm{mg} / \mathrm{g}$ mouse in a similar volume (64). Methylene blue dye was added to trace the path of the solution. Mice were sacrificed after 30 minutes, and blood was collected for CCK measurement using the CCK bioassay method (21). $I l d r 1^{-/-}$and wild-type mice used in these experiments were obtained by breeding of heterozygous mice. Both male and female mice, ages 8 weeks or older were used. Plasma from 3 mice was pooled to obtain one CCK concentration from the bioassay. Each bar in graphs in Figure 5 represents data obtained from a minimum of 3 individual assays.

CCK secretion by intestinal cells. The proximal small intestine of wild-type CCK-EGFP and Ildr1 $1^{-1}$ CCK-EGFP mice was harvested and everted on wires, and the ends were tied with suture. The everted intestine was incubated in HBSS containing $1 \mathrm{mM}$ EDTA and $1.5 \mathrm{mM}$ DTT for 10 minutes on ice and then transferred to HBSS containing $1 \mathrm{mM}$ EDTA for 10 minutes at $37^{\circ} \mathrm{C}$. The tube was shaken vigorously for 2 to 4 minutes, and the dissociated cells were collected by centrifugation. Cells were washed twice with HBSS containing $0.1 \%$ BSA and then incubated with $0.2 \mathrm{mg}$ Dispase (Life Technologies) and $0.3 \mathrm{mg}$ collagenase (CLPSA grade, Worthington Biochemical Corporation) in HBSS for 10 minutes at $37^{\circ} \mathrm{C}$. Cells were filtered through a 100- $\mu \mathrm{m}$ filter and washed 3 times with HBSS containing $10 \mathrm{mM}$ HEPES, $\mathrm{pH}$ 7.4, 0.1\% BSA, and $5 \mathrm{mM}$ glucose. Dispersed cells were counted and aliquoted in 24-well plates. Lipoproteins (100 $\mu \mathrm{g}$ protein $/ \mathrm{ml}$ final concentration) in the presence or absence of $\mathrm{C} 12(100 \mu \mathrm{M}$ final, $20 \mathrm{mM}$ stock prepared in isopropanol) were added to the wells, and the plate was incubated for 30 minutes at $37^{\circ} \mathrm{C}$ in a water bath. After 30 minutes, cells were chilled on ice for 5 minutes and centrifuged at $1,500 \mathrm{~g}$ (average $g$ ) for 5 minutes at $4^{\circ} \mathrm{C}$, and the supernatant was carefully removed for measurement of CCK release by radioimmunoassay (8). Assays were performed in triplicate or quadruplicate, and data were normalized to basal release.

$\left[\mathrm{Ca}^{2+}\right]_{i}$ fluorescence measurements and image analysis. EGFP-positive intestinal cells from wild-type CCK-EGFP or $\mathrm{Ildr}^{-1^{--}}$CCK-EGFP mice were isolated by FACS as described previously (8). Cells were loaded with $2.5 \mu \mathrm{M}$ X-rhod- 1 and incubated at $37^{\circ} \mathrm{C}$ for 40 minutes. Prior to imaging, cells were rinsed 3 times with HEPES-buffered HBSS, pH 7.4, containing $5 \mathrm{mM}$ glucose. Cells were plated on acid-washed and poly-D-lysine-coated glass cover slips and secured in a perfusion chamber. This chamber was mounted onto the stage of a Zeiss Axio Observer equipped with GFP filter (excitation BP470/40; emission BP525/50), RFP filter (excitation BP560/40; emission BP630/70), and a Coolsnap ES2 high-resolution CCD camera. Cells were imaged with a $\times 40$ oil objective. Multidimensional images were collected using MetaMorph software (Molecular Devices). Individual CCK cells were first identified by EGFP fluorescence, after which RFP filters were used for real-time recordings using X-rhod-1 fluorescence imaging. Stage positions were programmed to allow imaging of multiple fields in each experiment. Cells were imaged for 3 time points in culture media (containing calcium) before addition of test substances (C12 alone, lipoproteins with or without $\mathrm{C} 12, \mathrm{KCl}) . \mathrm{Ca}^{2+}$ fluorescence measurements in the presence of L-phenylalanine were performed as described previously (8).

Changes in intracellular fluorescence were analyzed using Metamorph software. Viable CCK cells were identified by EGFP positivity and a minimum 
$10 \%$ change in intracellular calcium fluorescence following $\mathrm{KCl}(50 \mathrm{mM})$ stimulation. Thus, EGFP-positive cells that responded to $\mathrm{KCl}$ were selected as an analysis region. Green and red channel intensities were recorded across time for these 2 regions. For each experimental condition, 10-30 data points were recorded over 3 to 15 minutes. The first 3 time points were reserved to establish baseline X-rhod-1 intensity (average value designated as Fo). At the fourth time point, lipoprotein with or without $\mathrm{C} 12$ was added (final concentrations of $100 \mu \mathrm{g}$ protein/ml for lipoproteins and $100 \mu \mathrm{M}$ for $\mathrm{C} 12 ; 10 \mathrm{mM}$ C12 stock solution in isopropanol). The cells were imaged for the remaining time. Fluorescence intensity was estimated from measurements of the $\mathrm{X}$-rhod-1 intensity at minimal and maximal $\left[\mathrm{Ca}^{2+}\right]_{\mathrm{i}}$ as the pseudoratio $(\Delta F / F)$ indicated by the following formula: $\Delta F / F=(F m-F o) / F o$, where $F m$ stands for measured fluorescence intensity (65). Cells were counted as responsive if their $\Delta \mathrm{F} / \mathrm{F}$ value increased more than $10 \%$ over baseline.

Statistics. Results are expressed as mean \pm SEM. Mean differences between 2 groups were examined by a 2 -tailed Student's $t$ test, and mean differences among several groups were examined by 1-way ANOVA, with the TukeyKramer post-hoc test, using GraphPad InStat 3.10 and Prism 5.03 for Windows (GraphPad Software Inc.), respectively. $P$ values of less than 0.05 were considered significant.

Study approval. All rodent work was performed in accordance with Duke University's approved institutional protocols and guidelines.
Supplemental material. Additional data are available in the Supplemental Methods and Supplemental Figures 1-7.

\section{Acknowledgments}

This work was supported by NIH grants DK091946 and DK064213 and the Duke Comprehensive Cancer Center Core facility. We would like to thank Mirta Mihilovic for sharing her protocols for lipoprotein preparations, Cathy Bittner for managing the mouse colony, and Faraz Majeed for help with purification of bacterially expressed ILDR1 proteins for immunization into rabbits. The authors also thank Sam Johnson and Yasheng Gao for their help with image acquisition and acknowledge Duke University's Light Microscopy Core Facility. Finally, we thank Mike Cook for standardizing the parameters for flow cytometric measurements of DiI uptake in $\mathrm{CHO}$ cells.

Received for publication December 28, 2012, and accepted in revised form May 23, 2013.

Address correspondence to: Rodger A. Liddle, Box 3913, Duke University Medical Center, Durham, North Carolina, 27710, USA. Phone: 919.681.6380; Fax: 919.668.0412; E-mail: rodger.liddle@duke.edu.
1. Calam J, Ellis A, Dockray GJ. Identification and measurement of molecular variants of cholecystokinin in duodenal mucosa and plasma. Diminished concentrations in patients with celiac disease. J Clin Invest. 1982;69(1):218-225.

2. Liddle RA, et al. Effects of a novel cholecystokinin (CCK) receptor antagonist, MK-329, on gallbladder contraction and gastric emptying in humans. Implications for the physiology of CCK. J Clin Invest. 1989;84(4):1220-1225.

3. Cantor $\mathrm{P}$, et al. The effect of the cholecystokinin receptor antagonist MK-329 on meal-stimulated pancreaticobiliary output in humans. Gastroenterology. 1992;102(5):1742-1751.

4. Wolkowitz OM, Gertz B, Weingartner H, Beccaria L, Thompson K, Liddle RA. Hunger in humans induced by MK-329, a specific peripheral-type cholecystokinin receptor antagonist. Biol Psychiatry. 1990;28(2):169-173.

5. Rehfeld JF, Friis-Hansen L, Goetze JP, Hansen TVO. The biology of cholecystokinin and gastrin peptides. Curr Top Med Chem. 2007;7(12):1154-1165.

6. Woods SC, Seeley RJ, Porte D Jr, Schwartz MW. Signals that regulate food intake and energy homeostasis. Science. 1998;280(5368):1378-1383.

7. Liou AP, et al. The extracellular calcium-sensing receptor is required for cholecystokinin secretion in response to L-phenylalanine in acutely isolated intestinal I cells. Am J Physiol Gastrointest Liver Physiol. 2011;300(4):G538-G546.

8. Wang Y, et al. Amino acids stimulate cholecystokinin release through the $\mathrm{Ca}^{2+}$-sensing receptor. Am J Physiol Gastrointest Liver Physiol. 2011; 300(4):G528-G537.

9. McLaughlin J, Grazia Luca M, Jones MN, D’Amato M, Dockray GJ, Thompson DG. Fatty acid chain length determines cholecystokinin secretion and effect on human gastric motility. Gastroenterology. 1999; 116(1):46-53

10. Feltrin KL, et al. Comparative effects of intraduodenal infusions of lauric and oleic acids on antropyloroduodenal motility, plasma cholecystokinin and peptide YY, appetite, and energy intake in healthy men. Am J Clin Nutr. 2008; 87(5):1181-1187.

11. Guimbaud R, et al. Intraduodenal free fatty acids rather than triglycerides are responsible for the release of CCK in humans. Pancreas. 1997;14(1):76-82.
12. McLaughlin JT, Lomax RB, Hall L, Dockray GJ, Thompson DG, Warhurst G. Fatty acids stimulate cholecystokinin secretion via an acyl chain length-specific, $\mathrm{Ca}^{2+}$-dependent mechanism in the enteroendocrine cell line STC-1. J Physiol. 1998; 513(1):11-18

13. Benson RS, Sidhu S, Jones MN, Case RM, Thompson DG. Fatty acid signalling in a mouse enteroendocrine cell line involves fatty acid aggregates rather than free fatty acids. J Physiol. 2002;538(pt 1):121-131.

14. Liou AP, et al. The G-protein-coupled receptor GPR40 directly mediates long-chain fatty acid-induced secretion of cholecystokinin. Gastroenterology. 2011; 140(3):903-912.

15. Glatzle J, et al. Chylomicron components activate duodenal vagal afferents via a cholecystokinin A receptor-mediated pathway to inhibit gastric motor function in the rat. J Physiol. 2003;550(pt 2):657-664.

16. Glatzle J, Darcel N, Rechs AJ, Kalogeris TJ, Tso P, Raybould HE. Apolipoprotein A-IV stimulates duodenal vagal afferent activity to inhibit gastric motility via a CCK1 pathway. Am J Physiol Regul Integr Comp Physiol. 2004;287(2):R354-R359.

17. Hauge H, Patzke S, Delabie J, Aasheim HC. Characterization of a novel immunoglobulin-like domain containing receptor. Biochem Biophys Res Commun. 2004;323(3):970-978.

18. Bihain BE, Yen FT. Free fatty acids activate a high-affinity saturable pathway for degradation of low-density lipoproteins in fibroblasts from a subject homozygous for familial hypercholesterolemia. Biochemistry. 1992;31(19):4628-4636.

19. Yen FT, et al. Molecular cloning of a lipolysis-stimulated remnant receptor expressed in the liver. J Biol Chem. 1999;274(19):13390-13398

20. Wu J-H, et al. The adaptor protein $\beta$-arrestin2 enhances endocytosis of the low density lipoprotein receptor. J Biol Chem. 2003;278(45):44238-44245.

21. Tashiro M, Samuelson LC, Liddle RA, Williams JA. Calcineurin mediates pancreatic growth in protease inhibitor-treated mice. Am J Physiol Gastrointest Liver Physiol. 2004;286(5):G784-G790.

22. Green GM, Levan VH, Liddle RA. Interaction of dietary protein and trypsin inhibitor on plasma cholecystokinin and pancreatic growth in rats. $A d v$ Exp Med Biol. 1986;199:123-132.

23. Liddle RA, Misukonis MA, Pacy L, Balber AE Cholecystokinin cells purified by fluorescence-acti- vated cell sorting respond to monitor peptide with an increase in intracellular calcium. Proc Natl Acad Sci U S A. 1992;89(11):5147-5151.

24. Mangel AW, et al. Calcium-dependent regulation of cholecystokinin secretion and potassium currents in STC-1 cells. Am J Physiol. 1993; 264(6 pt 1):G1031-G1036.

25. Feng J, et al. Calcium-sensing receptor is a physiologic multimodal chemosensor regulating gastric G-cell growth and gastrin secretion. Proc Natl Acad Sci US A. 2010;107(41):17791-17796.

26. Reimann F, Habib AM, Tolhurst G, Parker HE, Rogers GJ, Gribble FM. Glucose sensing in L cells: a primary cell study. Cell Metab. 2008;8(6):532-539.

27. Kalogeris TJ, Fukagawa K, Tso P. Synthesis and lymphatic transport of intestinal apolipoprotein A-IV in response to graded doses of triglyceride. J Lipid Res. 1994;35(7):1141-1151

28. Hussain MM, Kancha RK, Zhou Z, Luchoomun J, Zu H, Bakillah A. Chylomicron assembly and catabolism: role of apolipoproteins and receptors. Biochim Biophys Acta. 1996;1300(3):151-170.

29. Green PH, Tall AR, Glickman RM. Rat intestine secretes discoid high density lipoprotein. JClin Invest. 1978;61(2):528-534.

30. Forester GP, Tall AR, Bisgaier CL, Glickman RM. Rat intestine secretes spherical high density lipoproteins. J Biol Chem. 1983;258(9):5938-5943.

31. Brunham LR, et al. Intestinal ABCA1 directly contributes to HDL biogenesis in vivo. J Clin Invest. 2006; 116(4):1052-1062.

32. Kindel T, Lee DM, Tso P. The mechanism of the formation and secretion of chylomicrons. Atheroscler Suppl. 2010;11(1):11-16.

33. Abumrad NA, Davidson NO. Role of the gut in lipid homeostasis. Physiol Rev. 2012;92(3):1061-1085.

34. Ji Y, Li X, Tso P. Intestinal fatty acid absorption. Immunol Endocr Metab Agents Med Chem. 2009;9(1):60-73.

35. Attie AD. ABCA1: at the nexus of cholesterol, HDL and atherosclerosis. Trends Biochem Sci. 2007; 32(4):172-179.

36. Anderson RG, Brown MS, Goldstein JL. Role of the coated endocytic vesicle in the uptake of receptor-bound low density lipoprotein in human fibroblasts. Cell. 1977;10(3):351-364.

37. Hussain MM. Structural, biochemical and signaling properties of the low-density lipoprotein receptor gene family. Front Biosci. 2001;6:D417-D428. 
38. Yen FT, et al. Identification of a lipolysis-stimulated receptor that is distinct from the LDL receptor and the LDL receptor-related protein. Biochemistry. 1994; 33(5):1172-1180.

39. Kibbey RG, Rizo J, Gierasch LM, Anderson RGW. The LDL receptor clustering motif interacts with the clathrin terminal domain in a reverse turn conformation. J Cell Biol. 1998;142(1):59-67.

40. Magun AM, Mish B, Glickman RM. Intracellular apoA-I and apoB distribution in rat intestine is altered by lipid feeding. J Lipid Res. 1988; 29(9):1107-1116.

41. Rodriguez MD, Kalogeris TJ, Wang XL, Wolf R, Tso P. Rapid synthesis and secretion of intestinal apolipoprotein A-IV after gastric fat loading in rats. Am J Physiol Regul Integr Comp Physiol. 1997; 272(4):R1170-R1177.

42. Fujimoto K, Cardelli JA, Tso P. Increased apolipoprotein A-IV in rat mesenteric lymph after lipid meal acts as a physiological signal for satiation. Am J Physiol. 1992;262(6 pt 1):G1002-G1006.

43. Fujimoto K, Fukagawa K, Sakata T, Tso P. Suppression of food intake by apolipoprotein A-IV is mediated through the central nervous system in rats. J Clin Invest. 1993;91(4):1830-1833.

44. Fujimoto K, et al. Effect of intravenous administration of apolipoprotein A-IV on patterns of feeding, drinking and ambulatory activity of rats. Brain Res. 1993;608(2):233-237.

45. Glatzle J, Kalogeris TJ, Zittel TT, Guerrini S, Tso P, Raybould HE. Chylomicron components mediate intestinal lipid-induced inhibition of gastric motor function. Am J Physiol Gastrointest Liver Physiol. 2002;282(1):G86-G91.

46. Borck G, et al. Loss-of-function mutations of ILDR1 cause autosomal-recessive hearing impairment DFNB42. Am J Hum Genet. 2011; 88(2):127-137

47. Masuda S, et al. LSR defines cell corners for tricellular tight junction formation in epithelial cells. J Cell Sci. 2011;124(4):548-555.

48. Riazuddin S, et al. Tricellulin is a tight-junction protein necessary for hearing. Am J Hum Genet. 2006; 79(6):1040-1051

49. Higashi T, et al. Analysis of the 'angulin' proteins LSR, ILDR1 and ILDR2 - tricellulin recruitment, epithelial barrier function and implication in deafness pathogenesis. J Cell Sci. 2013;126(4):966-977.

50. Krieger M, Stern DM. Series introduction: multiligand receptors and human disease. JClin Invest. 2001; 108(5):645-647.

51. Herz J, Strickland DK. LRP: a multifunctional scavenger and signaling receptor. J Clin Invest. 2001; 108(6):779-784.

52. Sagare AP, Deane R, Zlokovic BV. Low-density lipoprotein receptor-related protein 1: A physiological $\mathrm{A} \beta$ homeostatic mechanism with multiple therapeutic opportunities. Pharmacol Ther. 2012; 136(1):94-105.

53. He X, Semenov M, Tamai K, Zeng X. LDL receptor-related proteins 5 and 6 in Wnt/ $\beta$-catenin signaling: arrows point the way. Development. 2004; 131(8):1663-1677.

54. Ye Z-j, Go G-W, Singh R, Liu W, Keramati AR, Mani A LRP6 protein regulates low density lipoprotein (LDL) receptor-mediated LDL uptake. J Biol Chem. 2012; 287(2):1335-1344.

55. Valacchi G, Sticozzi C, Lim Y, Pecorelli A. Scavenger receptor class B type I: a multifunctional receptor. Ann N Y Acad Sci. 2011;1229(1):E1-E7.

56 . Krieger M. Scavenger receptor class B type I is a multiligand HDL receptor that influences diverse physi- ologic systems. J Clin Invest. 2001;108(6):793-797.

57. Farrell JJ. Digestion and absorption of nutrients and vitamins. In: Feldman M, Friedman LS, Brandt LJ, eds. Sleisenger \& Fordtran's Gastrointestinal and Liver Disease: Pathophysiology, Diagnosis, Management. 8th ed. Philadelphia, Pennsylvania: Saunders Elsevier; 2006: 2147-2197.

58. Chandra R, Samsa L, Vigna S, Liddle R. Pseudopodlike basal cell processes in intestinal cholecystokinin cells. Cell Tissue Res. 2010;341(2):289-297.

59. Schumaker VN, Puppione DL. Sequential flotation ultracentrifugation. Methods Enzymol. 1986; 128:155-170

60. Terpstra AHM, Pels AE III. Isolation of plasma lipoproteins by a combination of differential and density gradient ultracentrifugation. Fresenius $Z$ Anal Chem. 1988;330(2):149-151.

61. Mihovilovic M, Robinette JB, DeKroon RM, Sullivan PM, Strittmatter WJ. High-fat/high-cholesterol diet promotes a S1P receptor-mediated antiapoptotic activity for VLDL. J Lipid Res. 2007;48(4):806-815.

62. Pitas R, Innerarity T, Weinstein J, Mahley R. Acetoacetylated lipoproteins used to distinguish fibroblasts from macrophages in vitro by fluorescence microscopy. Arterioscler Thromb Vasc Biol. 1981; 1(3):177-185

63. Innerarity TL, Pitas RE, Mahley RW. Lipoprotein-receptor interactions. Methods Enzymol. 1986; 129:542-565

64. Liddle RA, Green GM, Conrad CK, Williams JA. Proteins but not amino acids, carbohydrates, or fats stimulate cholecystokinin secretion in the rat. Am J Physiol. 1986;251(2):G243-G248.

65. Takahashi A, Camacho P, Lechleiter JD, Herman B. Measurement of intracellular calcium. Physiol Rev. 1999;79(4):1089-1125. 